\title{
Limited Attention, Competitive Information and Earnings Announcement Effect
}

\author{
Tian $\mathrm{Xu}^{1 *}$ \\ ${ }^{1}$ School of Economics and Management, Nanjing University of Science \& Technology, Nanjing, Jiangsu 210094, \\ China \\ *Corresponding author.Email: mxutian@njust.edu.cn
}

\begin{abstract}
This paper takes the 2007-2019 semi-annual and annual report of Chinese A-share listed companies as the research object, using multiple regression to examine the existence of earnings announcement effect and the relationship between investors' attention, competitive information and earnings announcement effect. We find that there is no typical earnings announcement effect in Chinese stock market, but the market can identify different types of earnings information and react differently, manifesting as overreaction to good news and underreaction to bad news. Relevant information has spillover effect while irrelevant information has distracting effect.
\end{abstract}

Keywords: Limited attention; unexpected earnings; competitive information; earnings announcement effect

\section{INTRODUCTION}

Earnings announcements, as important information reflecting companies' fundamental value, have significant impact on investors' decisions. In the case of semi-strong market, stock prices should adjust quickly when earnings announcement is released and earnings information should be fully and completely reflected in stock price. However, the Post-Earnings Announcement Drift (PEAD) violates theoretical expectation. The earnings announcement effect is first discovered by Ball and Brown (1968) [1], that is, market do not respond to the new information immediately when the earnings information is released. 'Good news' is followed by positive drift and 'bad news' is followed by negative drift. Beaver (1968) [2] focuses on stock price during the earnings announcement period, comparing the degree of price change before- and after-announcement to study the impact of earnings information on stock excess returns. He finds that the changes in companies stock prices and trading volume after announcement are higher than nonannouncement period. Later, lots of scholars conduct empirical tests on the anomaly. Although there are differences in samples, intervals and methods, most of them confirms the anomaly.

Some domestic scholars also test Chinese stock market. Their conclusions almost show that earnings data has information content, but there are no standard unifying statements about price trend after earnings announcement. Wu and Huang (1997) find that investors reacted in advance before earnings information is released [3]. After the information was released, stocks with high EPS have increasing cumulative abnormal returns, stocks with low EPS have declining cumulative abnormal returns. Subsequently, Zhao (1998) increases the sample and time span based on their research, finding that unexpected earnings and stocks' abnormal returns exist statistically positive correlation [4]. Chen and Liu (1999) show that daily trading volume increase significantly before and after earnings announcements [5]. Ruan, Zhang and Ma (2003) find that there is no significant earnings announcements effect in Chinese stock market [6]. Stock price and financial income have opposite trends. Wu and $\mathrm{Wu}$ (2003) find that the surplus inertia strategy can obtain significant excess returns [7]. Zhang (2004) finds that Chinese stock market has postannouncement adjustment effect, but adjustment direction is opposite to unexpected earnings [8]. Feng et al. (2015) find that PEAD phenomenon does exist in Chinese stock market and there are two special price movement patterns___ "Lost Belt" and "50-day cycle effect" [9]. Jiang et al. (2017) find that the impacts of 'good news' and 'bad news' on trading volume are asymmetrical [10].

One of explanations for the PEAD phenomenon is that investors' attention is limited and it takes time and cost for them to interpret information. When investors are faced with a large amount of information, which will 
distract investors' attention. As a result, investors insufficient response to information in short-time. This underreaction then slowly disappears and stock price adjusts to right level. However, there are still controversies about whether competitive information distracts investors' attention or has spillover effect. Hirshleifer et al. (2009) find that irrelevant information in competitive information will distract investors' attention [11]. Yu and Wang (2010) believe that information has spillover effects, which is beneficial to mutual verification and prediction between relevant information and improves the efficiency of investors' classification perception [12].

This paper studies the relationship between investors' limited attention, competitive information and earnings announcement effects. On the one hand, we can explore the existence of earnings announcement effects and the price trend after announcement. On the other hand, there are still controversies in this field. This paper can add research in this field and provide support for controversial conclusions.

\section{RESEARCH HYPOTHESIS}

When new information arrives, investors can only interpret and absorb information slowly due to process information takes time and cost. Therefore, new information cannot be quickly and fully reflected in stock price.

Hypothesis 1: After earnings announcement, good news is followed by positive drift and bad news is followed by negative drift.

Earnings information disclosed on the same day contains both peer relevant information and non-peer irrelevant information. There is comparability among peer companies. Earnings information of peer companies is more likely to attract investors' attention than those of non-peer companies. Investors can evaluate the target company's performance by referring to the performance of peer companies. The industry information contained in the earnings information of peer companies can also be used as a supplement, helping investors understand the performance of the whole industry, the company's industry position and profit-driven. Investors' expectations and valuation of the company can be revised and stock market responses to earnings information can be improved. Irrelevant information has little reference significance for investors, so the spillover effect is limited. However, as potential investment target, investors may pay attention to some irrelevant information in order to adjust portfolio. In this case, irrelevant information will only distract attention and reduce market responses to earnings information.

Hypothesis 2: Relevant information has a spillover effect, which can increase stock market immediate responses and reduce lagging responses to unexpected earnings. Irrelevant information has a distracting effect, which will weaken the market immediate responses and increase lagging responses to unexpected earnings.

\section{RESEARCH DESIGN}

\subsection{Variable definition}

This paper's dependent variable is cumulative excess return (CAR), we use the risk adjustment method to calculate the excess return of individual stocks, which is calculated according to the actual return and the adjusted return of the CAPM model. We define the earnings announcement date as 'day 0 '.

At the same time, we define three independent variables. (1) standard unexpected earnings (SUE);(2) the number of relevant information (RNUMBER) and the number of irrelevant information (IRNUMBER).

And there are six control variables:(1) size: the natural logarithm of total assets at the end of the fiscal year;(2) book-to-market value ratio $(\mathrm{B} / \mathrm{M}) ;(3)$ price momentum (MOM) is defined as the accumulated excess returns from 80 days to 20 days before day 0 ;(4) liquidity: use the amihud illiquidity index as a substitute for liquidity;(5) institutional shareholding ratio (Institution);(6) annual effect (Year), which controls the year of fiscal report disclosure.

\subsection{Model construction}

Using multiple regression analysis to test the impact of investors' limited attention on the post-earnings announcement effect. The regression models are as follows:

$$
C A R_{\left[t_{1}, t_{2}\right]}=\alpha+\beta_{1} S U E+\beta_{2} R N U M B E R+
$$
$\beta_{3} S U E * R N U M B E R+\beta_{4} I R N U M B E R+\beta_{5} S U E *$ IRNUMBER $+\beta_{6}$ CONTROLS $+\varepsilon$

$\mathrm{CAR}_{[-5,0]}$ reflects the market's immediate response to unexpected earnings, $\mathrm{CAR}_{[1,21]}$ and $\mathrm{CAR}_{[1,63]}$ reflects the market's lagging response to unexpected earnings.

\subsection{Sample selection}

The firms that are included in this study are Shanghai and Shenzhen A-share listed companies. The research objects are those companies' semi-annual reports and annual reports from January 2007 to June 2019, and exclude financial companies and ST companies, finally obtains 27641 earnings announcement data. The data set downloaded from CSMAR database and companies' financial reports.

\section{RESULTS}

To compare the abnormal returns on day 0 with average cumulative abnormal returns (ACAR) over the subsequent 5, 10, 21 and 63 trading days. Table 1 
documents the result. On average, the abnormal return on day 0 is close to 0 , the ACAR over the subsequent 5,10, 21 and 63 days is significantly negative. When we distinguish standard unexpected earnings (SUE) by sign, some different patterns emerge. Under 'bad news', negative day 0 abnormal returns are followed by negative drifts in returns over the subsequent 5 and 63 trading days. This could be interpreted as the stock market underreaction to bad news. On the other hand, under 'good news', positive day 0 abnormal returns are followed by negative drift in returns over subsequent
5,10,21 and 63 days. This could be interpreted as the stock market overreaction to good news. Overall, the results in this table suggest that there is no earnings announcement effect and price trend described in hypothesis 1 . The market can identify different types of earnings information and react differently, manifesting as overreaction to good news and underreaction to bad news. Abnormal returns after good news and bad news continue to drift negatively, which indirectly proved that Chinese stock market has not reached semi-strong efficiency.

Table 1 Average cumulative abnormal returns (ACAR) on day 0 and subsequent trading days

\begin{tabular}{|c|c|c|c|c|c|c|}
\hline \multicolumn{2}{|c|}{} & \multicolumn{5}{c|}{ ACAR } \\
\hline & Obs. & {$[-5,0]$} & {$[1,5]$} & {$[1,10]$} & {$[1,21]$} & {$[1,63]$} \\
\hline All events & 27641 & -0.01 & $-0.041^{* * *}$ & $-0.01^{* *}$ & $-0.014^{* * *}$ & $-0.031^{* * *}$ \\
\hline Bad news & 13775 & $-0.066^{* * *}$ & $-0.042^{* * *}$ & 0.006 & 0.003 & $-0.017^{* * *}$ \\
\hline Good news & 13866 & $0.046^{* * *}$ & $-0.04^{* * *}$ & $-0.025^{* * *}$ & $-0.031^{* * *}$ & $-0.045^{* * *}$ \\
\hline
\end{tabular}

Using the number of earnings announcements from peer(non-peer) companies released on the same day to measure relevant(irrelevant) information. To examine the impact of relevant and irrelevant information on earnings announcement effect I carry out one test and the results are shown in Table 2 and Table 3.

Table 2 shows stock market immediate responses to relevant or/and irrelevant information. Regressions I and III do not contain control variables, regressions II, IV and $\mathrm{V}$ contain control variables. It suggests that regardless of whether the control variables are added, the coefficient of SUE is significantly positive, indicating that the market's immediate reaction increases with the increase in unexpected earnings. Stock market can obtain positive excess returns after good news and negative excess returns after bad news. The coefficient of SUE*RNUMBER in regression I is 0.0001 , which is significant at the $1 \%$ level, indicating that as the relevant information increases, the market immediate responses to unexpected earnings increases. In other words, relevant information has a spillover effect, earnings information which form peer companies can help investors understand the company's earnings information and make more reasonable decisions. The coefficient of SUE*IRNUMBER in regression III is -0.00002 , which is significant at the $10 \%$ level, indicating that as the irrelevant information increases, the market's immediate response to unexpected earnings weakens. In other words, disclosure of irrelevant information has a distracting effect, causing the market's immediate response to unexpected earnings to decline. After adding the control variables, the regression results of II and IV are similar to those of I and III. It proves that disclosure of relevant information has a spillover effect and disclosure of irrelevant information has a distracting effect. Regression $\mathrm{V}$ contains relevant information, irrelevant information and their interaction terms with SUE. The coefficient of SUE*RNUMBER is 0.0001 , which is significant at the $1 \%$ statistical level, while the coefficient of SUE*IRNUMBER close to 0 , indicating that stock market immediate responses to unexpected earnings is more sensitive to relevant information than irrelevant information.

Table 2 The impact of relevant/irrelevant information on market immediate response

\begin{tabular}{|l|c|c|c|c|c|}
\hline \multirow{3}{*}{ Variables } & \multicolumn{5}{|c|}{ CAR $_{[-5,0]}$} \\
\cline { 2 - 6 } & \multicolumn{2}{|c|}{ Relevant information } & Irrelevant information & All \\
\cline { 2 - 6 } & I & II & III & IV & V \\
\hline SUE & $0.0008^{* * *}$ & $0.0009^{* * *}$ & $0.0008^{* * *}$ & $0.0009^{* * *}$ & $0.0008^{* * *}$ \\
\hline RNUMBER & $-0.0010^{* * *}$ & $-0.0010^{* * *}$ & & & -0.0001 \\
\hline SUE*RNUMBER & $0.0001^{* *}$ & $0.0001^{* *}$ & & & $0.0001^{* *}$ \\
\hline
\end{tabular}




\begin{tabular}{|l|c|c|c|c|c|}
\hline IRNUMBER & & & $-0.0001^{* * *}$ & $-0.0001^{* * *}$ & $-0.0001^{* * *}$ \\
\hline SUE*IRNUMBER & & & $-0.00002^{*}$ & $-0.00002^{*}$ & -0.0000 \\
\hline Control variables & NO & YES & NO & YES & YES \\
\hline $\mathrm{R}^{2}$ & $0.89 \%$ & $1.68 \%$ & $1.31 \%$ & $2.34 \%$ & $2.35 \%$ \\
\hline F value & 82.63 & 52.34 & 122.73 & 73.48 & 60.52 \\
\hline
\end{tabular}

Table 3 shows the results of stock market lagging responses to relevant or/and irrelevant information. First, pay attention to the results of relevant information. The coefficients of SUE*RNUMBER in regressions I and IV are -0.0001 and -0.0002 and both are significant, indicating that as the relevant information increases, market lagging responses to unexpected earnings decreases. Secondly, pay attention to the results of irrelevant information. The coefficient of SUE*UNRNUMBER in regression II is close to 0 and in regression $\mathrm{V}$ is 0.00001 , which is significant at the $10 \%$ level, that is, in the long-term window of one quarter after day 0 , the market lagging responses increase with the increase of irrelevant information. Market lagging responses are coordinated with market immediate responses in Table 2. As the relevant information increases, the market immediate responses to unexpected earnings increase, while the lagging responses weaken; as the irrelevant information increases, the market immediate responses to unexpected earnings weaken, while the lagging responses increase. Finally, move attention to regression III and VI. The coefficients of SUE*RNUMBER in regression III and VI are negative and significant, while the coefficients of SUE*IRNUMBER are close to 0 , indicating that relevant information can reduce the market lagging responses to unexpected earnings. Stock market lagging responses to unexpected earnings is more sensitive to relevant information than irrelevant information.

Table 3 The impact of relevant/irrelevant information on market lagging response

\begin{tabular}{|l|c|c|c|c|c|c|}
\hline \multirow{2}{*}{ Variables } & \multicolumn{3}{|c|}{ CAR $_{[1,21]}$} & \multicolumn{3}{c|}{ CAR $_{[1,63]}$} \\
\cline { 2 - 7 } & I & II & III & IV & V & VI \\
\hline SUE & $-0.0016^{* * *}$ & $-0.0013^{* * *}$ & $-0.0014^{* * *}$ & $-0.0031^{* * *}$ & $-0.0029^{* * *}$ & $-0.0031^{* * *}$ \\
\hline RNUMBER & $0.0006^{* * *}$ & & 0.0001 & $0.0009^{* * *}$ & & 0.0001 \\
\hline SUE*RNUMBER & $-0.0001^{*}$ & & $-0.0001^{*}$ & $-0.0002^{* * *}$ & & $-0.0002^{* * *}$ \\
\hline IRNUMBER & & $0.00005^{* * *}$ & $0.00005^{* * *}$ & & $0.00008^{* * *}$ & $0.00007^{* * *}$ \\
\hline SUE*IRNUMBER & & 0.0000 & -0.0000 & & $0.00001^{*}$ & 0.0000 \\
\hline Control variables & YES & YES & YES & YES & YES & YES \\
\hline R & $1.96 \%$ & $2.02 \%$ & $2.03 \%$ & $3.75 \%$ & $3.79 \%$ & $3.80 \%$ \\
\hline F value & 61.47 & 63.16 & 51.97 & 119.77 & 121.02 & 99.28 \\
\hline
\end{tabular}

Note: $* * *$ and $* * *$ symbols denote statistical significance at the $10 \%, 5 \%$ and $1 \%$ level.

\section{CONCLUSION}

It is a controversial topic whether competitive information will distract investors' attention or has spillover effect. Based on the limited attention hypothesis, this paper examines the information content of Chinese accounting data and the existence of earnings announcement effects. Using multiple regression model to study the relationship between investors' attention, competitive information and the market's sensitivity to earnings information. The conclusion includes: (1) Market reacts differently to different types of earnings information and the post-announcement drift manifests as overreaction to good news and underreaction to bad news. (2) Dividing earnings information into relevant and irrelevant information according to whether it belongs to the same industry. Relevant information has spillover effect, which can help investors understand earnings information and increase the market immediate responses and reduce lagging responses to unexpected earnings. Irrelevant information has distracting effect, which can weaken the market immediate responses and increase lagging responses to unexpected earnings. 


\section{ACKNOWLEDGMENT}

This work was supported by National Natural Science Foundation of China (61303022), Natural Science Major Project of Jiangsu Higher Education Institutions (17KJA520002), and Nanjing Scientific \& Technological Innovation Project for Outstanding Overseas Returnees.

\section{REFERENCES}

[1] Ball R., Brown P. An Empirical Evaluation of Accounting Income Numbers, Journal of Accounting Research, 1968, pp.159-178.

DOI: https://doi.org/10.2307/2490232

[2] Beaver, W. The Information Content of Annual Earnings Announcements, Journal of Accounting Research,1968, pp.67-92. DOI: https://doi.org/10.2307/2490070

[3] Wu Shinong, Huang Zhigong. An Empirical Study on Listed Companies' Profit Information Report, Stock Price Changes and Stock Market Efficiency, Accounting Research, 1997, pp. 13-18.

[4] Zhao Yulong. Information Content of Accounting Earnings Disclosure: Empirical Evidence from Shanghai Stock Market, Economic Research, 1998, pp. $42-50$.

[5] Chen Xiao, Chen Xiaoyue, Liu Zhao. Research on the usefulness of A-share earnings reports: Empirical evidence from the Shanghai and Shenzhen stock markets, Economic Research, 1999, pp. 21-28.

[6] Ruan Yi, Zhang Hanjiang, Ma Chaoqun. An Empirical Study on the Announcement Effect of A-
Share Income in Shenzhen Stock Market, System Engineering, 2003, pp.17-22.DOI: https://doi.org/10.3969/j.issn.10014098.2003.02.004

[7] Wu Shinong, Wu Chaopeng. An Empirical Study of "Price Inertia Strategy" and "Earnings Inertia Strategy" in my country's Stock Market, Economic Science, 2003, pp. 41-50.

[8] Zhang Qingcui. Research on the delayed response anomaly of my country's stock market to regular reports, Economic Science, 2004, pp. 55-64.

[9] Feng Haihan, Ma Zhekun, Wu Yifu. An Empirical Study of PEAD in China's A-Share Main Board Market, Contemporary Economy, 2015, pp. 1016.DOI: $\quad$ https://doi.org/10.3969/j.issn.10079378.2015.07.003

[10] Jiang Jing, Huang Wanxuan, Luo Ronghua. The asymmetric impact of earnings announcements on stock trading volume: An empirical study based on my country's A-share market, Investment Research, 2017, pp. 136-157.

[11] Hirshleifer D., Lim S. S., Teoh S. H. Driven to Distraction: Extraneous Events and Underreaction to Earnings News, Journal of Finance, 2009, pp. 2289-2325. DOI: https://doi.org/10.1111/j.15406261. 2009.01501.x

[12] Yu Lisheng, Wang Yanyan. Information Competitive Disclosure, Investor Attention and Information Dissemination Efficiency, Financial Research, 2010, pp. 112-135. 